\title{
Acute leukemia in pregnancy: Case series from a tertiary care institute
}

\author{
Ravindra Kumar Peta ${ }^{1}$, Harsha P Panchal ${ }^{1,{ }^{*}}$, Apurva Patel ${ }^{1}$, Sonia Parikh ${ }^{1}$, Animesh Agarwal ${ }^{1}$, Duncan Khanikar ${ }^{1}$ and Nikhil \\ Himthani $^{1}$ \\ ${ }^{1}$ Department of Medical Oncology, The Gujarat Cancer Research Institute, Ahmedabad, Gujarat, India
}

\begin{abstract}
Background: Acute leukemia in pregnancy is estimated to occur in less than one in one lakh pregnancies. Management of these patients differs by the trimester in which they present, because of the differential sensitivity of the fetus to chemotherapy during the three trimesters. Because of the rarity of this situation, there is scarcity of data on the management of these patients.

Materials and method: We included patients with acute leukemia diagnosed and treated during pregnancy at our institute and reviewed 3 successive patients for this case series.

Results and conclusion: Acute leukemia in pregnancy presents a unique challenge for treatment and requires multidisciplinary co-ordination for treatment. When judiciously managed, good outcomes of disease of mother and fetus can be achieved. Our three patients included one in each trimester; the first trimester patient underwent medical termination of pregnancy and has successfully completed treatment. The second trimester patient underwent induction chemotherapy and delivered a healthy baby. The patient diagnosed in the third trimester delivered a pre-term healthy baby during treatment and continues to be on chemotherapy.
\end{abstract}

Keywords: acute leukemia in pregnancy; medical termination of pregnancy; chemotherapy.

*Corresponding author: Dr. Harsha P Panchal, Professor and HOD, Department of Medical Oncology, The Gujarat Cancer REsearch Institute, Ahmedabad, Gujarat, India. Mobile no: 9825940769; Email: drharshapanchal@gmail.com

Received 18 December 2020; Revised 10 February 2021; Accepted 25 February 2021; Published 3 March 2021

Citation: Peta RK, Panchal HP, Patel A, Parikh S, Agarwal A, Khanikar D, Himthani N. Acute leukemia in pregnancy: Case series from a tertiary care institute. J Med Sci Res. 2021; 9(2):8590. DOI: http://dx.doi.org/10.17727/JMSR.2021/9-13

Copyright: (c) 2021 Peta RK et al. Published by KIMS Foundation and Research Center. This is an open-access article distributed under the terms of the Creative Commons Attribution License, which permits unrestricted use, distribution, and reproduction in any medium, provided the original author and source are credited.

\section{Introduction}

Cancers in pregnancy coexist at incidence of $0.1 \%$. The frequency and site of cancer are similar to those of non-pregnant women of the same age [1]. The incidence of acute leukemia occurring in pregnancy is one in one lakh pregnancies [2]. Of the acute leukemia in pregnancy, acute myeloid leukemia (AML) occurs in two thirds followed by acute lymphoblastic leukemia (ALL). Acute leukemia untreated during pregnancy may result in maternal and fetal mortality [3], while delay in treatment impacts the rates of remission. However, treatment outcomes following chemotherapy are similar in 
pregnant women as compared with non-pregnant women $[4,5]$.

Drug metabolism is adversely affected by pregnancy due to increase in plasma volume, the third space presence in the form of amniotic sac and changes in renal and hepatic metabolism [6]. Cytotoxic agents with molecular weight of less than $400 \mathrm{kDa}$ can cross the placental barrier [7] but the fetal malformation risk seems to be lower than that might be predicted from animal data but is increased when combination agents are used. However, data regarding these parameters is scarce given the paucity of research in such a clinical setting, namely pregnant receiving chemotherapy for acute leukemia, and therefore not many clinicians have used standard dosages based on body surface area (BSA). Another concern is that nutritional deficiencies due to co-existence of pregnancy, disease and ongoing chemotherapy may adversely affect fetal growth [8].

Cytarabine, Vincristine and anthracyclines (in different permutations) form integral parts of nearly all drug regimens in acute leukemia. Cytarabine and anthracyclines are used in both myeloid and lymphoid leukemias, of which anthracyclines are considered relatively safe as they have a molecular weight $>500 \mathrm{kDa}$; are hydrophilic molecules and are metabolized by placental P-Glycoprotein. However, cytarabine has been associated with limb deformities [9]. Vincristine is predominantly used in ALL and it appears to be safe during third trimester of pregnancy [10].

\section{First trimester (0-13 weeks)}

Pre-embryonic stage occurs from fertilization until 17 days after conception, rapid cell division occurs during this phase. Cytotoxic insult during this phase often results in miscarriage; however, if repair of this damage occurs the pregnancy may still proceed with no long term effects. The embryonic phase (2-8 weeks after conception) is the organogenesis phase and chemotherapy insult may result in end organ damage (heart, neural tube and limbs) and this is irreversible more often than not $[11,12]$. The CNS, renal system and gastrointestinal (GI) tract exhibit growth and differentiation throughout the fetal phase (8-38 weeks) and as such they remain susceptible to toxicity of chemotherapeutic agents [8].

Hence termination of pregnancy is indicated prior to treating acute leukemia diagnosed in the first trimester of pregnancy. The decision to treat acute leukemia during this phase should be taken with extreme caution and requires thorough counseling of the family with regard to the high risk of poor fetal outcomes.

\section{Second and third trimester}

During this time there is a high risk of fetal growth retardation (IUGR), preterm delivery and even fetal death (IUD) but there appears to be no increase in the incidence of congenital malformations [13].

Chemotherapy for acute leukemia may be planned during the second and third trimesters of pregnancy, but the timing should be such that the pancytopenia that almost always ensues does not hinder delivery of the fetus.

\section{Materials and method}

Three successive patients with acute leukemia diagnosed during pregnancy at our institute were followed for diagnostic workup, management (of disease and of pregnancy) and outcomes of the same. Ethical approval was taken from the Institutional Ethics Committee and all patients gave informed consent prior to using their data.

\section{Results}

We detail below the patients and their clinical course, with a tabulated summary (Table 1).

Table 1: Patients details.

\begin{tabular}{|cclllll|}
\hline SN & Age/Sex & Diagnosis & Trimester & Treatment given & Fetal outcome & Disease status \\
\hline 1 & $27 / F$ & AML (Intermediate Risk) & 1st (11 wks) & $7+3 \rightarrow 3 \#$ HIDAC & $\begin{array}{l}\text { MTP at 11 } \\
\text { weeks }\end{array}$ & $\begin{array}{l}\text { Treatment complete; } \\
\text { Remission }\end{array}$ \\
2 & $27 / F$ & AML (Poor Risk) & 2nd (21 wks) & $7+3 \rightarrow 1 \#$ HIDAC & $\begin{array}{l}\text { NVD at 34 } \\
\text { weeks }\end{array}$ & $\begin{array}{l}\text { Post induction of remission, } \\
\text { marrow in relapse. }\end{array}$ \\
3 & $30 / F$ & B-ALL (Ph neg) & 3rd (28 wks) & VP-VDP-VP-VDP-VP & $\begin{array}{l}\text { LSCS at 32 } \\
\text { weeks }\end{array}$ & $\begin{array}{l}\text { Post Ph II induction: } \\
\text { Remission }\end{array}$ \\
\hline
\end{tabular}

7 + 3: 7 days cytarabine, 3 days daunorubicin; HIDAC: High dose ara-C; V: Vincristine, D: Daunorubicin; P: Prednisolone; wks: weeks. 


\section{Case 1}

A 27-year-old woman, primigravida at 11 weeks of gestation presented with complaints of generalized weakness and body ache for 10 days. Her complete blood count (CBC) showed severe anemia and thrombocytopenia; Bone marrow examination and flow cytometry along with karyotyping and conventional cytogenetics established a diagnosis of intermediate risk AML.

Pre-treatment workup for chemotherapy fitness was normal. Obstetric evaluation and fetal sonography showed a single live fetus at 11 weeks of gestation ( \pm 2 days). The family was advised regarding various treatment options and the high risk of fetal adverse effects with chemotherapy in the first trimester of pregnancy. Requesting time for deliberation she took discharge on request and returned two weeks later after having undergone a medical termination of pregnancy (MTP) with an outside obstetrician. Obstetrician re-evaluation was done, which revealed no abnormality or retained products of conceptus. Patient was for induction chemotherapy with $3+7$ regimen (3 days Daunorubicin +7 days Cytarabine). She received chemotherapy as planned with minimal tolerance issues; post induction absolute neutrophil count (ANC) nadir (nil) was achieved 8 days after completion. Bone marrow examination for response assessment showed that she was in remission and was therefore given consolidation chemotherapy with 3 cycles of HIDAC (High dose cytarabine) regimen.

The patient is presently 3 months post chemotherapy and is being reviewed on an outpatient basis with monthly manual differential counts. She continues to be in remission.

\section{Case 2}

A 27-year-old woman, primigravida at 21 weeks of gestation presented with complaints of generalized weakness along with low grade fever for 10 days. Her CBC showed severe anemia along with leukocytosis (with 70\% blasts) and thrombocytopenia. Bone marrow examination along with immunophenotyping established a diagnosis of AML. Karyotyping and conventional cytogenetics and revealed FLT3 positivity and she was categorized as having poor risk disease.

Obstetrician evaluation and fetal sonography showed a single live fetus at 21 weeks of gestation
( \pm 3 days). After extensive discussions with the family and informed consent, she was planned for induction chemotherapy with $3+7$ regimen. The post chemotherapy absolute neutrophil count (ANC) nadir was recorded after 15 days. Weekly antenatal scans during and post chemotherapy were normal and one week post count recovery scan suggested a gestational age of 26 weeks ( \pm 4 days). Bone marrow was in remission, and the patient was kept on watchful follow up with twice weekly hemograms.

Blast cells reappeared in peripheral smears 10 days later, with the pregnancy at 28 weeks of gestation. Obstetricians' opinion was sought regarding early delivery of pregnancy, and it was suggested to attempt to take the pregnancy as close to 34 weeks as possible. It was decided to give low dose cytarabine for 7 days. Disease activity appeared to be in control for a week, but blasts again started rising with fetal sonography normal. Consequently it was decided to restart high dose chemotherapy with HIDAC regimen (at around 31 weeks of gestation) with which blasts cleared from the peripheral smear by the 3rd day post chemotherapy. However disease control was maintained for only 2 weeks. Antenatal checkup and sonography showed a viable healthy fetus at 34 weeks of gestation and the patient was planned for normal vaginal delivery (NVD).

She delivered a healthy baby $(1.9 \mathrm{~kg}$ weight (Figure 1), within 2SD of expected weight for gestational age) and the labour and peripartum period was uneventful. The patient is presently one week postpartum, on supportive management for lower respiratory tract infection (LRTI) and transfusion support for persistent thrombocytopenia.

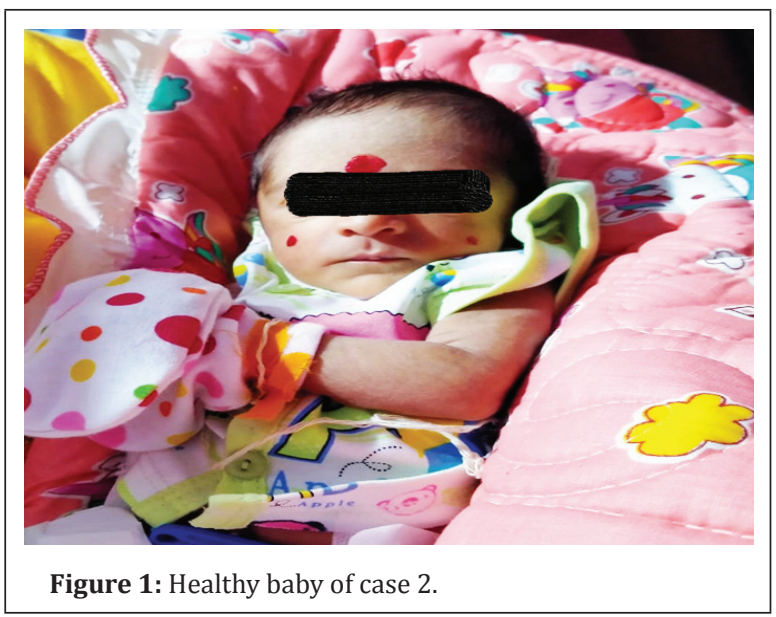




\section{Case 3}

A 30-year-old woman, 2nd gravida in 3rd trimester presented with complaints of generalized weakness along with low grade fever for 3 months. Her CBC showed moderate anemia along with severe thrombocytopenia; total white cell count was 8,100/ cu $\mathrm{mm}$ with $58 \%$ blasts. Bone marrow examination along with immunophenotyping established a diagnosis of Philadelphia chromosome negative, B-cell ALL.

Comorbidities included short stature along with severe kyphoscoliosis and a history of pre-term delivery (at 30 weeks) 3 years ago. There was no family history for any of these. Obstetrician evaluation and fetal sonography showed a single live fetus at 28 weeks of gestation ( \pm 3 days). She also had gestational hypertension which was managed with oral labetalol. After discussions with the family, it was decided to proceed with steroids (Prednisolone) with vincristine on a weekly basis. The treatment was continued for 4 weeks, with daunorubicin given on alternating weeks (total 2 doses). More aggressive treatment was not pursued in view of persistent fever and history of pre-term delivery (anticipating another pre-term delivery). Tolerance to chemotherapy was good and weekly obstetric evaluations showed no abnormalities. Peripheral smear showed clearing of blast cells by day 8 of chemotherapy with recovery of anemia and normalization of platelet counts.

Obstetricianopinionwastakenregardingtermination of pregnancy at this point, and it was advised to take the pregnancy as close to 34 weeks as possible. Betamethasone was advised for accelerating fetal lung maturation while we waited. One more dose was given (totaling 5 doses of VCR and 2 doses of daunorubicin) while continuing prednisolone. Soon after that the patient went into pre-term labour; she subsequently delivered a healthy baby $[1.4 \mathrm{~kg}$ weight (Figure 2), within 2SD of expected weight for gestational age] via lower segment caesarian section (LSCS) with an uneventful postpartum period. The patient is presently 4 weeks postpartum and has been started on BFM90 protocol based chemotherapy.

\section{Discussion}

Here we present three cases of acute leukemia in pregnancy in different trimesters. There are two important things to be considered in the management of acute leukemia in pregnancy. Firstly, the mother who needs cancer therapy and secondly the developing fetus who needs to be protected from the adverse effects of the antineoplastic drugs [14].

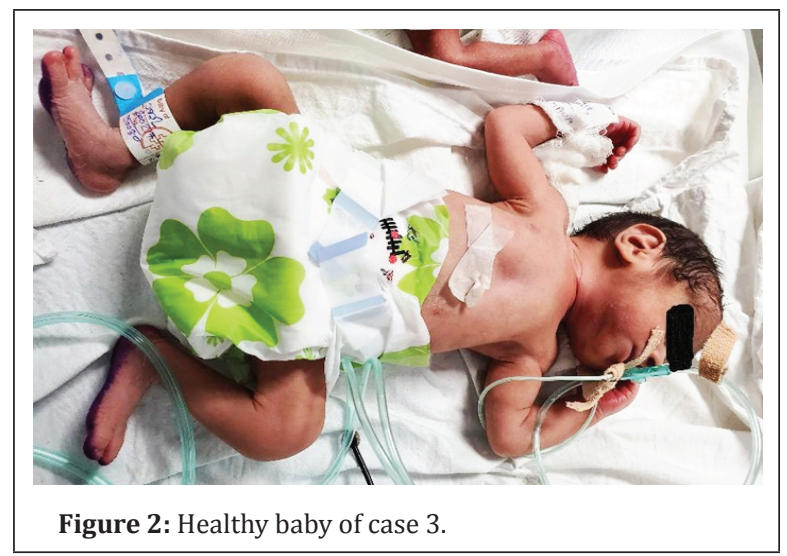

Several researchers have reported small series' of patient with acute leukemia in pregnancy [15-25]. Most show that delivering chemotherapy to these patients is feasible while maintaining maternal outcomes in line with those for non-pregnant women. The fetal outcomes, however, depend most upon the time at presentation. These are surmised in Table 2.

The largest reported case series is by Greenlund et al. [22] who treated 17 such patients over 37 years; they achieved remissions in about half of these cases. Out of 7 of these patients who presented in their first trimester, 4 underwent therapeutic abortions while 2 had spontaneous abortions; one patient received the full course of treatment and had a favourable fetal outcome $(1 / 7,14.3 \%)$. Overall, they had 9 favorable fetal outcomes and 10 remissions.

In our experience, the above results seem achievable with good maternal and fetal outcomes by timely management of the disease and its complications.

\section{Conclusions}

Acute leukemia in pregnancy is a rare condition that has to be managed by a multidisciplinary team. The therapeutic options and the related risks need to be discussed with each patient while involving the family on a case to case basis. Leukemia occurring in first trimester is managed by therapeutic abortion followed by chemotherapy, while those 
Table 2: Outcomes of acute leukemia in pregnancy.

\begin{tabular}{|c|c|c|c|}
\hline Study group & Number & Outcome of leukemia & Pregnancy and fetal outcomes \\
\hline Chelghoum et al. * [3] & $\begin{array}{l}\text { 31 AML (1st tm 9, 2nd tm 10, } \\
\text { 3rd tm 18) } \\
\text { ALL: } 6\end{array}$ & $34 \mathrm{CR}$ & $\begin{array}{l}\text { SA/MTP: } 15 \\
\text { NVD 13, LSCS 9; } 15 \\
\text { Healthy babies with no CM: } 23\end{array}$ \\
\hline Cardonick E et al.*[8] & $\begin{array}{l}89 \mathrm{AML} \\
63 \mathrm{ALL}\end{array}$ & Not mentioned & $\begin{array}{l}\text { CM: 6; IUGR: 12; IUFD: 11; Neonatal } \\
\text { deaths: } 2\end{array}$ \\
\hline Catanzarite et al.* [15] & 47 Acute leukemia & $\begin{array}{l}40 \text { treated } \\
7 \text { Not treated }\end{array}$ & Abortions 5, perinatal deaths 3 ; LI 32 \\
\hline Doney et al. [16] & 3 AML (2nd tm) & 2 CR, 1 Death & 1 MTP, 2 NVD with SGA \\
\hline Pizzuto et al. [17] & 9 ALL & Not mentioned & $6 \mathrm{NVD}, 3 \mathrm{FD}$ \\
\hline Awidi et al. [18] & 5 ALL & Not mentioned & $1 \mathrm{SA}, 4 \mathrm{NVD}$ \\
\hline Fassas et al. [19] & $\begin{array}{l}4 \mathrm{AML} \\
1 \mathrm{ALL}\end{array}$ & 4 CR, 1 PLA & $\begin{array}{l}\text { CS 1, NVD 3, MTP } 1 \\
\text { No CM }\end{array}$ \\
\hline Reynoso et al.[20] & $\begin{array}{l}3 \mathrm{AML} \\
3 \mathrm{ALL} \\
1 \mathrm{CML} \mathrm{BC}\end{array}$ & 4 CR, 2 PLA, 1 Not treated & 5 NVD, 2 LSCS, 2 CM \\
\hline Feliu et al. [21] & 5 Acute leukemia & $\begin{array}{l}3 \text { CR, } 1 \text { PLA, } 1 \text { death of } \\
\text { mother in } 5 \text { th month }\end{array}$ & 4 NVD with No CM \\
\hline Greenlund et al. [22] & $\begin{array}{l}15 \text { AML, } 2 \text { ALL } \\
1 \text { st tm 7, 2nd tm 7, 3rd tm } 3\end{array}$ & 9 CR1, 1 CR2 & 4 unintentional fetal loss, no CM \\
\hline Ali et al. [23] & $\begin{array}{l}6 \text { AML, } 2 \text { ALL } \\
\text { 1st tm 6, 2nd tm 4.(Total } 10 \\
\text { pregnancies) }\end{array}$ & $5 \mathrm{CR}$ & 2 SA, 5 MTP, 1 IUD \\
\hline Dilek et al. [24] & $\begin{array}{l}1 \mathrm{AML} \\
2 \mathrm{AML} \\
1 \mathrm{APML} \\
1 \mathrm{ALL}\end{array}$ & $\begin{array}{l}3 \text { preg: } C R>C R>\text { PLA } \\
2 \text { PLA } \\
\text { Mother expired. } \\
\text { CR }\end{array}$ & 3 LBW, 1MTP, No CM \\
\hline Menezes et al. [25] & $3 \mathrm{AML}$ & 3 PLA & 1 MTP, 2 LSCS, no CM \\
\hline
\end{tabular}

*Review article; CR-Complete remission; NVD-Normal vaginal delivery; CM-Congenital malformations; MTP-Medical termination of pregnancy; LBW-Low birth weight; LI-Live infant; SA-Spontaneous abortion; LSCS-Lower segment cesarean section; IUDIntrauterine death; tm-Trimester.

in second and third trimesters can be started on chemotherapy after appropriate informed consent has been taken. Continuous maternal and fetal monitoring is mandatory and one has to anticipate the complications that may arise during treatment due to pregnancy or due to the disease. With a multidisciplinary management approach we can improve outcomes of disease without adversely affecting the fetal outcome.

\section{Conflicts of interest}

Authors declare no conflicts of interest.

\section{References}

[1] Pavlidis NA. Coexistence of pregnancy and malignancy. Oncologist. 2002; 7:279-287.
[2] Haas VA. Pregnancy in association with newly diagnosed cancer: a population-based epidemiological assessment. Int J Cancer. 1984; 34:229-235

[3] Chelghoum Y, Vey N, Raffoux E, Huguet F, Pigneux A, et al. Acute leukemia during pregnancy: a report on 37 patients and a review of the literature. Cancer. 2005; 104(1):110117.

[4] Greenlund LJ, Letendre L, Tefferi A. Acute leukemia during pregnancy: a single institutional experience with 17 cases. Leuk Lymphoma. 2001; 41(5-6):571-577.

[5] Culligan DJ, Merriman L, Kell J, Parkerc J, Jovanovic JV, et al. The management of acute promyelocytic leukaemia presenting during pregnancy. Clin Leukemia. 2007; 1(3):183-191.

[6] El-Hemaidi I, Robinson SE. Management of haematological malignancy in pregnancy. Best Pract Res Clin Obstet Gynaecol. 2012; 26(1):149-160.

[7] Pacifici GM, Nottoli R. Placental transfer of drugs administered to the mother. Clin Pharmacokinet. 1995; 28(3):235-269. 
[8] Cardonick E, Iacobucci A. Use of chemotherapy during human pregnancy. Lancet Oncol. 2004; 5(5):283-291.

[9] Wagner VM, Hill JS, Weaver D, Baehner RL. Congenital abnormalities in baby born to cytarabine treated mother. Lancet. 1980; 2(8185):98-99

[10] Smit JW, Huisman MT, van Tellingen O, Wiltshire HR, Schinkel AH. Absence or pharmacological blocking of placental P-glycoprotein profoundly increases fetal drug exposure. J Clin Invest. 1999; 104(10):1441-1447.

[11] Azim HA, Pavlidis N, Peccatori FA. Treatment of the pregnant mother with cancer: a systematic review on the use of cytotoxic, endocrine, targeted agents and immunotherapy during pregnancy. Part II: Hematological tumors. Cancer Treat Rev. 2010; 36(2):110-121.

[12] Shapira T, Pereg D, Lishner M. How I treat acute and chronic leukemia in pregnancy. Blood Rev. 2008; 22(5):247-259.

[13] Abdel-Hady el-S, Hemida RA, Gamal A, El-Zafarany M, Toson E, et al. Cancer during pregnancy: perinatal outcome after in-utero exposure to chemotherapy. Arch Gynecol Obstet. 2012; 286(2):283-286.

[14] Karagiannis V, Daniilidis A, Klearhoy N, Mamopoulos A, Garipidou V, et al. Acute leukemia and pregnancy. Eur J Inflamm. 2007; 5(1):47-50.

[15] Catanzarite VA, Ferguson JE II. Acute leukemia and pregnancy. A review and management of outcome, 1972-1982. Obstet Gynecol Surv. 1984; 39(11):663-678.

[16] Doney RC, Kraemer KG, Shepard TM. Combination chemotherapy for acute myelocytic leukemia during pregnancy: three case reports. Cancer Treat Rep. 1979; 63(3):369-371.

[17] Pizzuto J, Aviles A, Noriega L, Niz J, Morales M, et al. Treatment of acute leukemia during pregnancy: presentation of nine cases. Cancer Treat Rep. 1980; 64(4-5):679-683.

[18] Awidi AS, Tarawneh MS, Shubair KS, Issa AA, Dajani YF. Acute leukemia in pregnancy: report of five cases treated with a combination which included a low dose of adriamycin. Eur J Cancer Clin Oncol. 1983; 19(7):881-884.

[19] Fassas A, Kartalis G, Klearchou N, Tsatalas K, Sinacos Z, et al. Chemotherapy for acute leukemia during pregnancy. Five case reports. Nouv Rev Fr Hematol. 1984; 26(1):19-24.

[20] Reynoso EE, Shepherd FA, Messner HA, Farquharson HA, Garvey MB, et al. Acute leukemia during pregnancy: the Toronto Study Group experience with long-term followup of children exposed in utero to chemotherapeutic agents. J Clin Oncol. 1987; 5(7):1098-1106.

[21] Feliu J, Suarez S, Ordonez A, Garcia-Paredes LM, GonzalesBaron M, et al. Acute leukemia and pregnancy. Cancer. 1988; 61:580-584.

[22] Greenlund LJ, Letendre L, Tefferi A. Acute leukemia during pregnancy: a single institutional experience with 17 cases. Leuk Lymphoma. 2001; 41(5-6):571-577.

[23] Ali R, Ozkalemkas F, Ozcelik T, Ozkocaman V, Ozan U, et al. Maternal and fetal outcomes in pregnancy complicated with acute leukemia: a single institutional experience with 10 pregnancies at 16 years. Leuk Res. 2003; 27(5):381-385.

[24] Dilek I, Topcu N, Demir C, Bay A, Uzun K, et al. Hematological malignancy and pregnancy: a single-institution experience of 21 cases. Clin Lab Haematol. 2006; 28(3):170-176.

[25] Menezes J, Emerenciano M, Pimenta F, Filho GG, Isis $Q$ et al. Occurrence of acute myeloid leukemia in young pregnant women. Clin Med Insights Blood Disord. 2008; 1:27-31. 